\title{
(2) OPEN ACCESS \\ Unplanned hospitalisations in older people: illness trajectories in the last year of life
}

\author{
Máté Szilcz (D) , ' Jonas W Wastesson (D) , ${ }^{1,2}$ Kristina Johnell (D) ,' \\ Lucas Morin (1) 1,3
}

- Additional supplemental material is published online only. To view, please visit the journal online (http://dx.doi. org/10.1136/bmjspcare-2020 002778)

${ }^{1}$ Department of Medical Epidemiology and Biostatistics, Karolinska Institutet, Stockholm Sweden

${ }^{2}$ Department of Neurobiology, Care Sciences and Society, Aging Research Center, Karolinska Institutet, Stockholm, Sweden ${ }^{3}$ Inserm CIC 1431, University Hospital of Besançon, Besançon, France

\section{Correspondence to}

Máté Szilcz, Department of Medical Epidemiology and Biostatistics, Karolinska Institutet, Stockholm 17177 Sweden; mate.szilcz@ki.se

Received 3 November 2020 Revised 14 January 2021 Accepted 24 March 2021

Check for updates

(C) Author(s) (or their employer(s)) 2021. Re-use permitted under CC BY-NC. No commercial re-use. See rights and permissions. Published by BM

\footnotetext{
To cite: Szilcz M Wastesson JW, Johnell K et al. BMJ Supportive \& Palliative Care Epub ahead of print: [please include Day Month Year]. doi:10.1136/ bmjspcare-2020-002778
}

\section{ABSTRACT}

Objective Unplanned hospitalisations can be burdensome for older people who approach the end of life. Hospitalisations disrupt the continuity of care and often run against patients' preference for comfort and palliative goals of care. This study aimed to describe the patterns of unplanned hospitalisations across illness trajectories in the last year of life.

Methods Longitudinal, retrospective cohort study of decedents, including all older adults ( $\geq 65$ years) who died in Sweden in 2015. We used nationwide data from the National Cause of Death Register linked at the individual level with several other administrative and healthcare registers. Illness trajectories were defined based on multiple-cause-of-death data to approximate functional decline near the end of life. Incidence rate ratios (IRR) for unplanned hospitalisations were modelled with zero-inflated Poisson regressions.

Results In a total of 77315 older decedents (53\% women, median age 85.2 years), the overall incidence rate of unplanned hospitalisations during the last year of life was 175 per 100 patient-years. The adjusted IRR for unplanned hospitalisation was $1.20(95 \% \mathrm{Cl}$ 1.18 to 1.21 ) times higher than average among decedents who followed a trajectory of cancer. Conversely, decedents who followed the trajectory of prolonged dwindling had a lowerthan-average risk of unplanned hospitalisation (IRR 0.66, 95\% Cl 0.65 to 0.68). However, these differences between illness trajectories only became evident during the last 3 months of life.

Conclusion Our study highlights that, during the last 3 months of life, unplanned hospitalisations are increasingly frequent. Policies aiming to reduce burdensome care transitions should consider the underlying illness trajectories.

\section{Key messages}

What was already known?

- Most older adults prefer avoiding care transitions near the end of life, yet prior studies have found an acceleration of hospital admissions close to death.

- Although hospital admissions are not necessarily unwarranted, avoiding burdensome emergency room visits and unplanned hospitalisations is often an important goal for patients with severe illness.

What are the new findings?

- Differences in unplanned hospitalisation across illness trajectories become evident during the last 3 months of life.

- Older people who died with cancer bear the highest burden of unplanned hospitalisations at the end of life.

What is their significance?

- Illness trajectories defined based on causes of death have obvious limitations but are nonetheless useful to differentiate end-of-life care patterns.

- Policies aiming at avoiding unwarranted care transitions near the end of life should tailor interventions to specific illness trajectories.

\section{INTRODUCTION}

Most older adults prefer to avoid care transitions at the end of life. ${ }^{12}$ Yet, such transitions-including hospital admissions and emergency department visitsare common and increasingly frequent as death approaches. ${ }^{3-8}$ Hospitalisation close to death can fragment the care continuity and planning, and have negative functional and psychological consequences. ${ }^{4}$ It can also lead to suboptimal quality of care, ${ }^{9}$ overdiagnosis and overtreatment. ${ }^{10}$ Hospitalisations are often stressful for patients and caregivers; 
disproportionately so for individuals with advanced age and/or physical and cognitive impairments. ${ }^{11}$

A substantial body of research has documented the accelerating pattern of hospital admissions at the end of life. However, most studies have not been able to distinguish between planned and unplanned hospitalisations. ${ }^{3} 5-8$ Yet, this distinction is essential since unplanned admissions have the potential to disorganise patient care. ${ }^{4}$ Although it should be noted that unplanned hospitalisations are not necessarily unwarranted or avoidable (and may even sometimes be in line with the patients' preferences), avoiding burdensome admissions becomes an important goal when the main priority of care is to maximise comfort and quality of life as death approaches. ${ }^{512-14}$

There is a lack of knowledge about which groups of individuals are at the highest risk of unplanned hospitalisations and at which point these are likely to occur throughout the end of life. Seriously ill individuals are expected to follow different trajectories of functional decline at the end of life, depending on their underlying illness. ${ }^{15} 16$ Hence, their use of hospital care at the end of life might also differ substantially. To verify this hypothesis, the present study aimed to describe the patterns of unplanned hospitalisations across illness trajectories in the last year of life. We used longitudinal administrative and healthcare data and assembled a mortality follow-back cohort including all older people who died in 2015 in Sweden.

\section{METHODS}

\section{Study design and population}

This was a retrospective cohort study of decedents including all older adults (age $\geq 65$ years) who died between 1 January and 31 December 2015 in Sweden. Decedents were excluded if their exact date of death was unknown, if their unique personal identifier had been reallocated to another person, or if their cause of death was either unknown, not reported or unspecific (online supplemental eFigure 1).

\section{Data sources}

We used routinely collected administrative data with national coverage in Sweden. Data from the National Cause of Death Register were linked to the National Patient Register, the Swedish Prescribed Drug Register, the Total Population Register and the Swedish Register of Education with a pseudonymised identifier (online supplemental eTable 1). ${ }^{17}$

\section{Illness trajectories}

Causes of death recorded on the death certificates were categorised into four distinct illness trajectories at the end of life, as proposed by Lunney et al $^{18}:$ (1) cancer, characterised by a short period of functional decline; (2) organ failure, marked by a longer period of functional limitations with intermittent acute decompensations; (3) prolonged dwindling, typical of older persons with neurodegenerative conditions and/ or frailty; (4) sudden death, namely none of the three abovementioned trajectories. ${ }^{19}$ International Classification of Disease-10th revision codes used to operationalise each illness trajectory are available in online supplemental eTable 2. In keeping with previous studies, we used a rule-based algorithm to allocate decedents to a single illness trajectory if the underlying and contributing causes of death were compatible with two or more trajectories. ${ }^{1820}$ The following hierarchy was applied: cancer $>$ prolonged dwindling $>$ organ failure $>$ sudden death. This hierarchy is based on the assumption that, when multiple trajectories are present, the faster progressing trajectory will determine most of the burden of functional decline over time. For instance, cancer is at the top of the hierarchy because a diagnosis of cancer have been shown to dominate other co-occurring diseases when included in the list of multiple causes of death. ${ }^{1921}$ The conceptual and operational difficulties of creating definite, clear-cut categories from complex events leading to death have been pointed out by others. ${ }^{15} 1822$ A particular challenge of delineating illness trajectories is that some decedents might follow none, some or all of these trajectories at the same time. However, in the absence of fine-grain data about actual longitudinal changes in physical and cognitive functions experienced near the end of lifewhich require extensive clinical information typically not available in routinely collected data-these four groups of illnesses have been found to be a good proxy for the pattern of late-life functional decline and care needs at the end of life. ${ }^{23}$

\section{Outcome}

Unplanned hospital admissions throughout the last year of life were captured in the National Patient Register, which covers $>99.9 \%$ of all inpatient care admissions and $>85 \%$ of specialised outpatient care visits. $^{24}$ Unplanned hospitalisations were defined as admissions recorded as being non-elective in the National Patient Register. We calculated the incidence rate of unplanned hospitalisations during the entire last year of life and during each of the 52 weeks (7-day hazard periods) before death. To prevent immortaltime bias-namely, considering hazard periods during which the study outcome cannot occur, time at risk was defined as the number of days when the persons were not hospitalised. ${ }^{25}$ Hospitalisations separated by 1 day or less were concatenated into a single episode in order to avoid counting transfers from one hospital unit to another as separate admissions. Incidence rates and their 95\% CIs were calculated per 100 personyears or per 100 person-weeks, as appropriate.

\section{Patient-level characteristics}

We extracted the main sociodemographic characteristics of decedents (eg, sex, age at death, marital status) from national registries. Chronic multimorbidity was 
operationalised as the number of chronic diseases out of a list of 60 pre-defined conditions, ${ }^{26}$ which were captured in the National Patient Register during the period ranging from 5 to 1 year before death (online supplemental eTable 3). We estimated the Hospital Frailty Risk Score ${ }^{27}$ based on the same data (online supplemental eTable 4). Education was defined as the lifetime highest attained educational level, and was categorised into primary, secondary and tertiary education based on the International Standard Classification of Education 1997 system $^{28}$ (online supplemental eTable 5). Polypharmacy was assessed during week 56-53 before death. It was calculated as the average number of prescription drugs (at the therapeutic/pharmacological subgroup level of the Anatomical Therapeutic Chemical classification system) that the decedents were exposed to across each of the 4 weeks preceding the last year of life. ${ }^{29}$

\section{Statistical analysis}

In the main analysis, we calculated the incidence rate of unplanned hospitalisations during the last year of life. Zero-inflated Poisson regression models were used to compute incidence rate ratios (IRRs) to compare the risk of unplanned hospitalisation across illness trajectories with regard to the average risk in the cohort. Zero-inflated Poisson models were warranted because of the substantial number of individuals with no unplanned admission ('excess zeros'). To confirm the appropriateness of the zero-inflated model, we first plotted the quantiles of the observed values of unplanned hospitalisations against the quantiles of their normal distribution (online supplemental eFigure 2). Second, we plotted the individual predicted probabilities under the zero-inflated model against that of the Poisson model ${ }^{30}$ (online supplemental eFigure 3). In both instances, deviations from the reference line indicated overdispersion with excess zeros. Finally, we compared the Akaike Information Criterion of the Poisson and zero-inflated models to see whether the latter obtained a better fit. Potential confounders were identified in the published literature and selected based on subject-matter knowledge. Analyses were thereafter adjusted for age at time of death, sex, marital status (married, single/divorced and widowed), chronic multimorbidity, ${ }^{26}$ Hospital Frailty Risk Score, ${ }^{27}$ polypharmacy ${ }^{29}$ and level of education (primary, secondary and tertiary). The logit function used to model the excess zeros was adjusted on the Hospital Frailty Risk Score and the cumulated length of hospital stays between 731 and 366 days before death. We also investigated the average weekly change in the rate of unplanned hospitalisations throughout the last year of life according to the decedents' illness trajectory. We calculated the relative IRRs as the effect estimate for the interaction between illness trajectory and time. For this, a generalised estimating equations model with Poisson family and log link function was fitted by using restricted cubic spline with knots at 9 , 6 and 3 weeks before death, with double-robust SEs to estimate unbiased $95 \%$ CIs. This analysis was adjusted for the same confounders as the primary analysis.

In prespecified sensitivity analysis, decedents with acute and potentially unexpected cause of death were identified by using a previously published algorithm $^{31}$ (online supplemental eTable 6) and thereafter excluded. The rational for this analysis was that death can still be largely unexpected regardless of the underlying illness trajectory: it is likely that these patients experienced unplanned hospitalisations that were clinically justified by an acute and life-threatening event, in a context where the goals of care were essentially curative. In post-hoc analysis, we repeated the IRR calculation of unplanned hospitalisation across illness trajectories during the last year of life using regular Poisson models, instead of the zero-inflated model. All analyses were performed with SAS software V.9.4 $4^{32}$ and R statistical software V.3.6.1, ${ }^{33}$ The present study was reported in keeping with the Reporting of studies Conducted using Observational Routinely-collected Data guidelines $^{34}$ (online supplemental eTable 7).

\section{RESULTS}

\section{Characteristics of the study population}

Out of 79473 individuals who died in 2015, 77315 (97.3\%) met our eligibility criteria (online supplemental eFigure 4). Their characteristics are shown in table 1. Overall, $30 \%$ of decedents followed a trajectory typical of cancer, $37 \%$ organ failure and $26 \%$ prolonged dwindling. Over $60 \%$ of those who followed a trajectory of prolonged dwindling were women, and only the cancer trajectory included more men than women. Median age at death was 85.2 years (IQR 77.7-90.7) with the decedents of the prolonged dwindling trajectory being the oldest while cancer decedents the youngest. One year before death, older people had a median of 4 (IQR 2-7) chronic diseases and were prescribed 5 (IQR 3-8) medications. Among the 5700 (7\%) older people who followed a trajectory of 'sudden death', the most common causes of death included acute myocardial infarction, pneumonia, sepsis, aortic aneurysm and dissection and fall-related injuries (online supplemental eTable 8).

\section{Incidence rate of unplanned hospitalisations}

Overall, decedents had on average 1.66 unplanned hospitalisations during their last year of life, with an incidence rate of 175 per 100 patient-years (table 2). Decedents who followed a trajectory of cancer had the highest incidence rate (231 per 100 patient-years), while individuals following a trajectory of prolonged dwindling had the lowest $(99$ per 100 patient-years). After adjusting on available confounders, decedents with cancer had 1.20 (95\% CI 1.18 to 1.21) times higher risk of unplanned 
Table 1 Characteristics of the study population

\begin{tabular}{|c|c|c|c|c|c|}
\hline & \multirow[b]{2}{*}{ Overall } & \multicolumn{4}{|c|}{ Illness trajectory } \\
\hline & & Cancer & Organ failure & Prolonged dwindling & Sudden death \\
\hline Decedents, no. & 77315 & 23213 & 28338 & 20064 & 5700 \\
\hline \multicolumn{6}{|l|}{ Sex, no. (\%) } \\
\hline Men & $36245(46.9)$ & $12413(53.5)$ & $13712(48.4)$ & $7283(36.3)$ & $2837(49.8)$ \\
\hline Women & $41070(53.1)$ & $10800(46.5)$ & $14626(51.6)$ & $12781(63.7)$ & $2863(50.2)$ \\
\hline \multicolumn{6}{|c|}{ Age at time of death, years } \\
\hline Median $\left(\mathrm{P}_{25}-\mathrm{P}_{75}\right)$ & $85.2(77.7-90.7)$ & $80.7(73.7-87)$ & $85.5(78.3-90.8)$ & $88.6(83.3-93.0)$ & $85.8(77.6-91.3)$ \\
\hline \multicolumn{6}{|l|}{ No. $(\%)$} \\
\hline $65-74$ years & $14140(18.3)$ & $6797(29.3)$ & $4804(17.0)$ & $1427(7.1)$ & $1112(19.5)$ \\
\hline $75-84$ years & $23993(31.0)$ & 8706 (37.5) & $8720(30.8)$ & $4997(24.9)$ & $1570(27.5)$ \\
\hline $85-94$ years & $32527(42.1)$ & $6991(30.1)$ & $12433(43.9)$ & $10647(53.1)$ & $2456(43.1)$ \\
\hline 95 years and older & $6655(8.6)$ & $719(3.1)$ & $2381(8.4)$ & $2993(14.9)$ & $562(9.9)$ \\
\hline \multicolumn{6}{|c|}{ Level of education, no. (\%) } \\
\hline Primary education & $35013(45.3)$ & 9119 (39.3) & $13503(47.6)$ & $9769(48.7)$ & $2622(46.0)$ \\
\hline Secondary education & $31443(40.7)$ & $10365(44.7)$ & $11175(39.4)$ & $7645(38.1)$ & $2258(39.6)$ \\
\hline Tertiary education & $9249(12.0)$ & $3352(14.4)$ & $3002(10.6)$ & $2197(10.9)$ & $698(12.2)$ \\
\hline Missing & $1610(2.1)$ & $377(1.6)$ & $658(2.3)$ & $453(2.3)$ & $122(2.1)$ \\
\hline \multicolumn{6}{|l|}{ Marital status, no. (\%) } \\
\hline Married & $25368(32.8)$ & $10191(43.9)$ & $8406(29.7)$ & $5149(25.7)$ & $1622(28.5)$ \\
\hline Single/divorced & $19067(24.7)$ & $5826(25.1)$ & $7493(26.4)$ & $4123(20.5)$ & $1625(28.5)$ \\
\hline Widowed & $32880(42.5)$ & $7196(31.0)$ & $12439(43.9)$ & $10792(53.8)$ & $2453(43.0)$ \\
\hline \multicolumn{6}{|l|}{ Frailty Risk Score } \\
\hline Median $\left(\mathrm{P}_{25}-\mathrm{P}_{75}\right)$ & $2.5(0.0-6.7)$ & $1.4(0.0-4.7)$ & $2.6(0.0-6.7)$ & $4.3(0.8-9.9)$ & $1.8(0.0-5.4)$ \\
\hline \multicolumn{6}{|l|}{ No. $(\%)$} \\
\hline Low & $51552(66.7)$ & $17716(76.3)$ & $18839(66.5)$ & $10853(54.1)$ & $4144(72.7)$ \\
\hline Moderate & $14210(18.4)$ & $3456(14.9)$ & $5598(19.8)$ & $4237(21.1)$ & $919(16.1)$ \\
\hline High & $11553(14.9)$ & $2041(8.8)$ & $3901(13.8)$ & $4974(24.8)$ & $637(11.2)$ \\
\hline \multicolumn{6}{|c|}{ Number of chronic diseases } \\
\hline Median $\left(\mathrm{P}_{25}-\mathrm{P}_{75}\right)$ & $4(2-7)$ & $4(2-6)$ & $5(3-8)$ & $4(2-6)$ & $3(2-6)$ \\
\hline \multicolumn{6}{|l|}{ No. $(\%)$} \\
\hline None & $5012(6.5)$ & $1480(6.4)$ & $1525(5.4)$ & $1331(6.6)$ & $676(11.9)$ \\
\hline One & $7725(10.0)$ & $2455(10.6)$ & $2231(7.9)$ & $2323(11.6)$ & $716(12.6)$ \\
\hline Two & $8940(11.6)$ & $2917(12.6)$ & $2538(9.0)$ & $2736(13.6)$ & $749(13.1)$ \\
\hline Three & $9418(12.2)$ & $3100(13.4)$ & $2835(10.0)$ & $2771(13.8)$ & $712(12.5)$ \\
\hline Four & $9155(11.8)$ & $2913(12.5)$ & $3105(11.0)$ & $2478(12.4)$ & $659(11.6)$ \\
\hline Five or more & $37065(47.9)$ & $10348(44.6)$ & $16104(56.8)$ & $8425(42.0)$ & $2188(38.4)$ \\
\hline \multicolumn{6}{|l|}{ Number of drugs } \\
\hline Median $\left(\mathrm{P}_{25}-\mathrm{P}_{75}\right)$ & $5(3-8)$ & $5(2-7)$ & $6(4-9)$ & $5(3-8)$ & $4(2-7)$ \\
\hline \multicolumn{6}{|l|}{ No. $(\%)$} \\
\hline $0-4$ & $31964(41.3)$ & $11469(49.4)$ & $9556(33.7)$ & 8009 (39.9) & $2930(51.4)$ \\
\hline $5-9$ & $34376(44.5)$ & 9188 (39.6) & $13267(46.8)$ & $9669(48.2)$ & $2252(39.5)$ \\
\hline$\geq 10$ & $10975(14.2)$ & $2556(11.0)$ & $5515(19.5)$ & 2386 (11.9) & $518(9.1)$ \\
\hline
\end{tabular}

hospitalisation than average. Conversely, decedents who followed a trajectory of prolonged dwindling and those who died in the sudden death trajectory had lower-than-average risks of unplanned hospitalisation (IRRs: $0.66(0.65-0.68)$ and $0.79(0.77-$ $0.82)$, respectively).

\section{Longitudinal changes in the incidence of unplanned hospitalisation}

Throughout the last year of life, the incidence rate of unplanned hospitalisation increased from 1.5 to 26.2 per 100 patient-weeks, regardless of illness trajectory or age (figure 1). There was a particularly steep increase among decedents who died suddenly (from 1.0 to 43.9 per 100 patient-weeks) and those with organ failure (from 1.8 to 38.0 per 100 patient-weeks). Detailed data are provided in online supplemental eTables 9 and 10, eFigure 5. We found that these incidence rates did not increase in a linear fashion and that differences between illness trajectories were marginal until the third month before death. Among decedents who followed a cancer trajectory, the rate of unplanned hospitalisations started increasing $\sim 16$ weeks before death, compared with $\sim 8$ weeks before death among older adults who died from organ failure and $\sim 4$ weeks 
Table 2 Incidence of unplanned hospitalisation during the last year of life, by illness trajectory

\begin{tabular}{|c|c|c|c|c|c|c|c|}
\hline & \multirow{2}{*}{$\begin{array}{l}\text { No. } \\
\text { decedents }\end{array}$} & \multicolumn{2}{|c|}{$\begin{array}{l}\text { Unplanned } \\
\text { hospitalisation }\end{array}$} & \multirow{2}{*}{$\begin{array}{l}\text { Number of } \\
\text { person-years* }\end{array}$} & \multirow{2}{*}{$\begin{array}{l}\text { Incidence rate per } \\
100 \text { person-years }\end{array}$} & \multicolumn{2}{|c|}{ Incidence rate ratio $(95 \% \mathrm{Cls}) \dagger$} \\
\hline & & No. events & Mean & & & Unadjusted & Adjusted‡ \\
\hline Overall & 77315 & 128156 & 1.66 & 73326 & 175 & $1.0(\operatorname{Ref}) \S$ & 1.0 (Ref) \\
\hline \multicolumn{8}{|l|}{ Trajectories } \\
\hline Cancer & 23213 & 49459 & 2.13 & 21447 & 231 & $1.22(1.21$ to 1.24$)$ & $1.20(1.18$ to 1.21$)$ \\
\hline Organ failure & 28338 & 52184 & 1.84 & 26824 & 195 & 1.09 (1.08 to 1.11$)$ & 1.04 (1.03 to 1.06$)$ \\
\hline Prolonged dwindling & 20064 & 19326 & 0.96 & 19552 & 99 & 0.57 (0.56 to 0.59$)$ & 0.66 (0.65 to 0.68$)$ \\
\hline Sudden death & 5700 & 7187 & 1.26 & 5503 & 131 & $0.73(0.71$ to 0.76$)$ & 0.79 (0.77 to 0.82$)$ \\
\hline
\end{tabular}

${ }^{*}$ The number of person-years at risk is not equal to the number of decedents because time at risk was defined as the number of days when the persons were not already hospitalised (ie, when the decedents were truly at risk of unplanned hospitalisation).

†Robust SEs were used to estimate the $95 \% \mathrm{Cls}$; incidence rate ratio obtained from zero-inflated Poisson models.

¥Adjusted for sex, age, education, marital status, frailty, number of chronic diseases, polypharmacy; decedents with missing data about education (2.1\% of total) were excluded from this analysis.

$\S$ The total study population was used as the reference category to compare the risks across illness trajectories to the average risk in the cohort.

among those who followed a trajectory of prolonged dwindling or sudden death.

During the last 3 months of life, we found substantial variations in the speed at which the rate of unplanned hospitalisations increased across the different illness trajectories. Older people who died from sudden causes had the fastest increase in the risks of unplanned hospitalisation (relative IRR: $1.12,95 \%$ CI 1.11 to 1.13 ), while decedents who followed a trajectory of cancer or prolonged dwindling trajectories had slower-than-average increases (table 3).

A more nuanced pattern emerged after we used restricted cubic splines to relax the assumption that the change in the risk of unplanned hospitalisation was linear over time. Figure 2 shows the relative
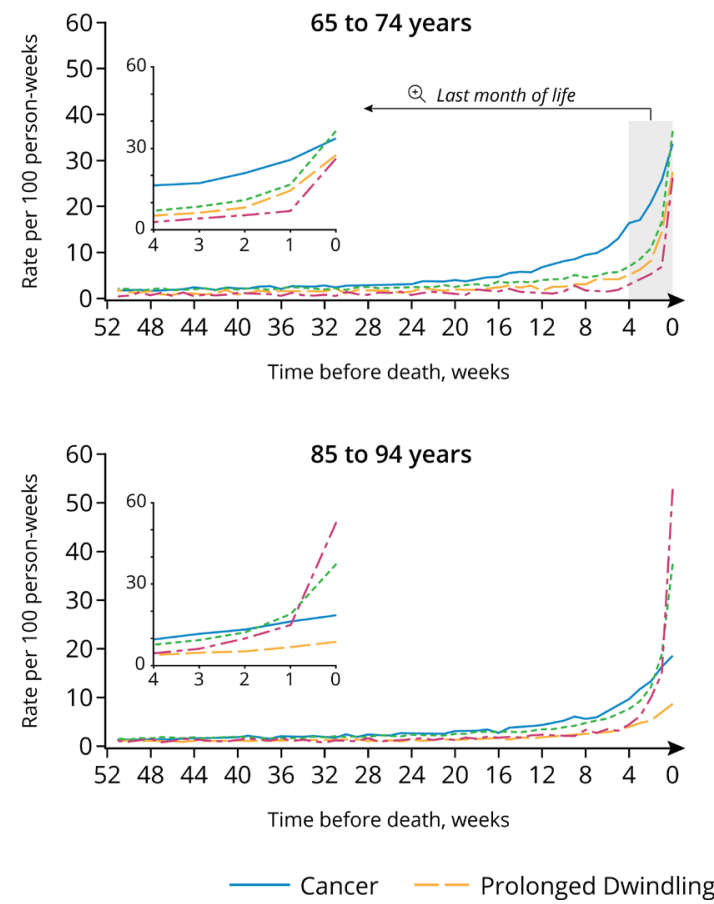

IRRs of unplanned hospitalisations during the last 12 weeks of life for each illness trajectory compared with the overall study population. Relative IRRs correspond to the speed at which the incidence of unplanned hospitalisation increased over time, week $_{12}$ being the reference period. Hence, the rate of unplanned hospitalisations among older people who followed a trajectory of cancer increased at a faster-than-average speed between the $12^{\text {th }}$ and the $3^{\text {rd }}$ week before death, after which we observed an acceleration among individuals who died from organ failure or sudden death while older people who followed a trajectory of prolonged dwindling experienced a substantially slower-than-average increase.
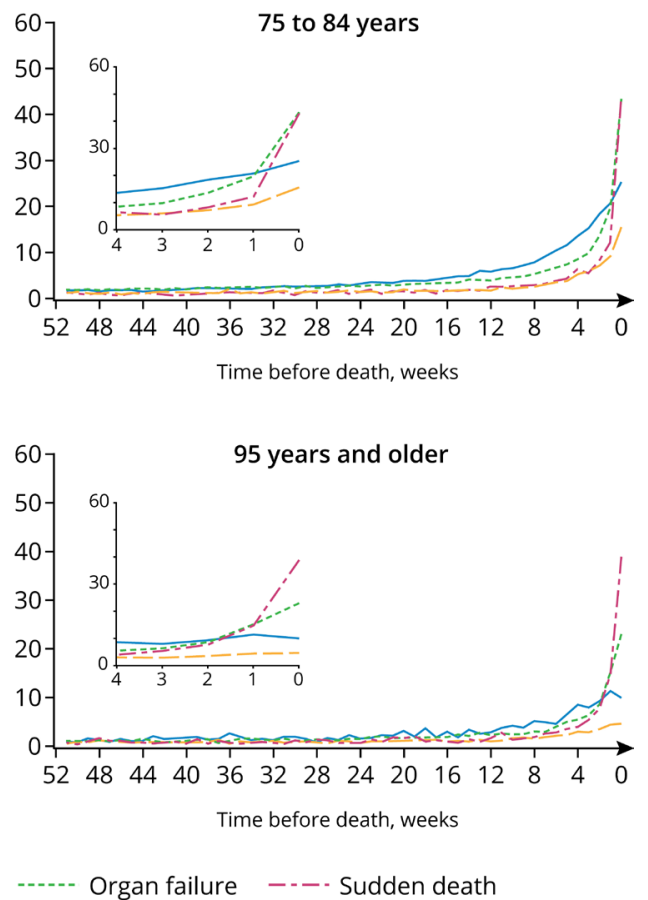

Figure 1 Incidence rate of unplanned hospitalisations throughout the last year of life, by age group and illness trajectory. 
Table 3 Average weekly change in the rate of unplanned hospitalisations throughout the last year of life, by illness trajectory

\begin{tabular}{|c|c|c|c|c|}
\hline & \multicolumn{4}{|c|}{ Relative incidence rate ratio $(95 \% \mathrm{Cls})^{*}$} \\
\hline & $\begin{array}{l}52-40 \text { weeks } \\
\text { before death }\end{array}$ & $\begin{array}{l}39-27 \text { weeks } \\
\text { before death }\end{array}$ & $\begin{array}{l}26-14 \text { weeks } \\
\text { before death }\end{array}$ & $\begin{array}{l}13-1 \text { weeks } \\
\text { before death } t\end{array}$ \\
\hline Overall $\ddagger$ & 1.0 (Ref) & 1.0 (Ref) & 1.0 (Ref) & 1.0 (Ref) \\
\hline \multicolumn{5}{|l|}{ Trajectories } \\
\hline Cancer & 1.01 (1.01 to 1.02$)$ & 1.01 (1.01 to 1.02$)$ & 1.01 (1.01 to 1.02$)$ & 0.97 (0.96 to 0.97 ) \\
\hline Organ failure & $1.00(0.99$ to 1.00$)$ & $1.00(0.99$ to 1.00$)$ & $1.00(0.99$ to 1.00$)$ & 1.04 (1.03 to 1.04$)$ \\
\hline Prolonged dwindling & 0.99 (0.98 to 0.99$)$ & $0.99(0.98$ to 1.00$)$ & $0.99(0.98$ to 1.00$)$ & 0.97 (0.96 to 0.97$)$ \\
\hline Sudden death & 1.00 (0.98 to 1.02$)$ & $0.99(0.97$ to 1.00$)$ & 0.99 (0.98 to 1.00$)$ & $1.12(1.11$ to 1.13$)$ \\
\hline
\end{tabular}

*Adjusted relative incidence rate ratio for the interaction between illness trajectory time, obtained from a log binomial model adjusted for sex, age, education, marital status, frailty, number of chronic diseases, polypharmacy. Decedents with missing data about education ( $2.1 \%$ of total) were excluded from this analysis. Robust SEs were used to estimate the $95 \%$ Cls. Relative incidence rate ratios can be interpreted as follow: the risk of unplanned hospitalisation among older people who follow a given illness trajectory changes in average at a faster (eg, 1.12 times faster) or slower (eg, 0.97 times slower) rate, considering the earliest week within the period (ie, week ${ }_{52}$ week $_{39}$, week ${ }_{26}$, week ${ }_{13}$ ) as the reference time point, than it does on average in the overall study population.

tWeek 1 corresponds to the last week before death.

¥The total study population was used as the reference category to compare the risks across illness trajectories to the average risk in the cohort.

\section{Sensitivity analyses}

The prespecified sensitivity analysis showed that about $45 \%$ of the study population had a potentially unexpected cause of death, regardless of their illness trajectory (online supplemental eTable 11). Repeating the main analysis after excluding decedents with potentially unexpected cause of death did not change the direction or magnitude of our results (online supplemental eTables 12 and 13, eFigure 6). In non-prespecified post-hoc analyses, the IRRs for unplanned hospitalisations throughout the entire last year of life did not change in a scientifically important or clinically relevant manner when fitting a regular Poisson model instead of the zero-inflated variant used in primary analysis (online supplemental eTable 14).

\section{DISCUSSION}

In this large, register-based cohort study, we found that the incidence of unplanned hospitalisations during the last year of life was comparable across illness trajectories until the third month before death. After this time point, unplanned hospitalisations became increasingly frequent and differences between illness trajectories became evident. The incidence of unplanned hospitalisations started increasing among decedents with cancer trajectory, followed by those with organ failure. Older people with a trajectory of prolonged dwindling (often characterised by dementia) experienced a more modest increase in the risk of unplanned hospitalisation, mostly during the final month of life.

Unplanned hospitalisations are frequent at the end of life. We found that $18 \%$ of older adults in Sweden have at least one unplanned hospitalisation during their last week of life. In comparison, 11\% of US Medicare beneficiaries in 2015 had at least one healthcare transition in their last 3 days of life. Overall, the incidence rate of unplanned hospitalisation in our cohort was low between 12 and 3 months before death and illness trajectories seem to offer little discriminative ability to differentiate unplanned hospitalisation during this

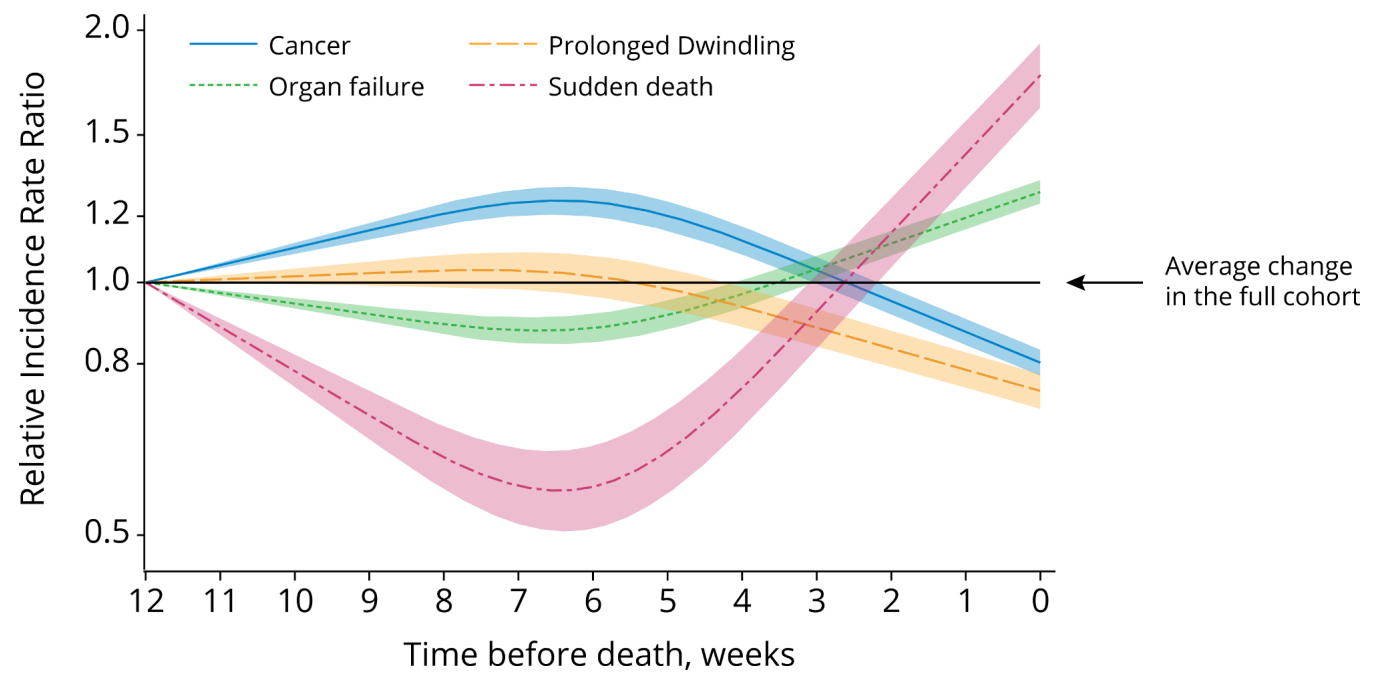

Figure 2 Change in the incidence rate of unplanned hospitalisations throughout the last 12 weeks of life, by illness trajectory. 
period. However, the patterns of unplanned hospitalisations started to diverge across illness trajectories during the last 3 months before death. Our finding that the incidence rate of unplanned hospitalisations increases close to death is consistent with previous studies, although with somewhat different timings. ${ }^{3-8}$

Overall, cancer decedents bear the highest burden of unplanned admissions during the last year of life, a finding well in line with a recent report from Public Health England. ${ }^{35}$ This may be partly attributable to the worsening of pain and other distressing symptoms as death approaches. Older people who died from organ failure had the second highest incidence of unplanned hospitalisation, with a steep acceleration near the end of life. This pattern may be connected with the increasingly frequent exacerbation of symptoms and acute deterioration of disease close to death, which sometimes warrant immediate inpatient care. Finally, individuals who followed a trajectory of 'prolonged dwindling' (most often characterised by dementia) had the lowest and slowest increase in incidence of unplanned admission during the last year of life. Their significant symptom burden, poorer-thanaverage access to symptom relief ${ }^{3637}$ and high levels of physical frailty at the end of life would suggest greater utilisation of emergency hospitalisation. However, their observed lower propensity of unplanned hospitalisation may be explained by difficulties in communicating and relatives acting as gatekeepers, and by the fact that they are more likely to live in nursing homes ${ }^{38}$ that provide more medical care than home-based care ${ }^{39}$ Older adults with sudden death had the highest incidence rate of unplanned hospitalisation during the last weeks of life. Their most common causes of death included events that are likely to result in necessary unplanned hospitalisation followed by imminent death, for example, acute myocardial infarction.

Unplanned hospitalisations close to death are not always avoidable and are sometimes in line with patients' preferences, but they can nonetheless have adverse outcomes. ${ }^{4-11} 4041$ Studies suggest that a substantial fraction of unplanned hospitalisations can be reduced by integrative anticipatory palliative care and advanced care planning. ${ }^{42-45}$ It has been also reported that routinely collected administrative data can be used to identify persons with potential palliative care needs. ${ }^{46}$ Our results indicate that the patterns of different illness trajectories should be considered when planning policies aiming to reduce unplanned hospitalisations, especially in the very last months before death. The unique hospitalisation pattern of decedents in the sudden death trajectory suggests that it is relevant to differentiate them from older people who could potentially benefit from integrated palliative care. However, basing decisions on the illness trajectories requires that the trajectories are identified prospectively and not based on causes of death. Future studies should investigate how well register data can be used to identify illness trajectories as older people near death.

Strengths of the study include routinely collected data with nearly $100 \%$ nationwide coverage which eliminates non-participation bias and reduces the risk of outcome misclassification as there is no recall or information bias. However, our findings should be interpreted with the following limitations in mind. First, retrospective cohorts of decedents have the potential to introduce selection effects and immortaltime bias, ${ }^{47}$ which we addressed by conducting thorough sensitivity analyses. Second, illness trajectories were identified at the time of death and not at the outset of the underlying condition, which may have led to some degree of exposure misclassification (ie, the applied illness trajectory hierarchy might have caused overestimation of the cancer trajectory) and immortal-time bias (exposure time might have been misclassified for those who did not have any condition in a portion of the last year of life that could explain unplanned hospitalisations). Second, defining illness trajectories into four broad categories is an oversimplification of the clinical processes that lead to death in old age. Yet, despite their obvious limitations, these illness trajectories remain a useful tool to approximate the late-life functional decline patterns that warrant different health services needs at the end of life. ${ }^{23}$ Third, the data used in the present study do not allow for forming a judgement about whether or not each individual unplanned hospitalisation was clinically and ethically appropriate, or whether it resulted in health gains or losses for the patients. Our population-level findings can thus be used to inform public health strategies and care commissioning choices, but not to evaluate individual decisions in clinical practice, which are made case-by-case with more detailed information about the healthcare needs of patients and about their preferences and priorities. Finally, our findings stem from the context of the Swedish universal healthcare system and may thus not be entirely transportable to other countries with different healthcare systems.

\section{CONCLUSION}

Unplanned hospitalisations are common at the end of life, especially during the last 3 months. Decedents belonging to different underlying illness trajectories had divergent patterns of unplanned hospitalisations during their last 3 months of life. This should be considered in healthcare policies aiming to reduce burdensome care transitions and improve comfort at the end of life. Future studies are warranted to investigate how illness trajectories can inform advance care planning and whether the observed trends in latelife unplanned hospitalisations are in keeping with patients' preferences and goals of care. 
Acknowledgements The authors wish to thank Michael Sachs for his helpful comments and suggestions regarding the statistical analysis.

Contributors LM and MS conceived and designed the study. MS performed the statistical analysis, interpreted the data, drafted and critically revised the manuscript. LM, JWW and KJ interpreted the data and critically revised the manuscript. KJ obtained funding, provided supervision, interpreted the data and critically revised the manuscript. LM is the guarantor of the study and data integrity. All authors gave approval for the final version of the manuscript and agree to be accountable for all aspects of the work.

Funding This work was supported by funding from the Swedish Research Council for Health, Working Life and Welfare (FORTE) and KID-funding. The sponsor had no role in study design, data collection and analysis, decision to publish or preparation of the manuscript.

Competing interests None declared.

Patient consent for publication Not required.

Ethics approval The study was approved by the Regional Ethical Review Board of Stockholm (dnr: 2016/1001-31/4).

Provenance and peer review Not commissioned; externally peer reviewed.

Data availability statement Data may be obtained from a third party and are not publicly available. Clinical data cannot be made publicly available because of privacy issues. However, additional results and aggregated findings are available in the supplementary files or on reasonable request.

Open access This is an open access article distributed in accordance with the Creative Commons Attribution Non Commercial (CC BY-NC 4.0) license, which permits others to distribute, remix, adapt, build upon this work noncommercially, and license their derivative works on different terms, provided the original work is properly cited, appropriate credit is given, any changes made indicated, and the use is noncommercial. See: http://creativecommons.org/licenses/by-nc/4. $0 /$.

\section{ORCID iDs}

Máté Szilcz http://orcid.org/0000-0002-9291-0559

Jonas W Wastesson http://orcid.org/0000-0001-7601-4319

Kristina Johnell http://orcid.org/0000-0003-0093-7699

Lucas Morin http://orcid.org/0000-0002-8486-8610

\section{REFERENCES}

1 Woodman C, Baillie J, Sivell S. The preferences and perspectives of family caregivers towards place of care for their relatives at the end-of-life. A systematic review and thematic synthesis of the qualitative evidence. BMJ Support Palliat Care 2016;6:418-29.

2 Higginson IJ, Sen-Gupta GJ. Place of care in advanced cancer: a qualitative systematic literature review of patient preferences. J Palliat Med 2000;3:287-300.

3 Van den Block L, Pivodic L, Pardon K, et al. Transitions between health care settings in the final three months of life in four EU countries. Eur J Public Health 2015;25:569-75.

4 Gill TM, Gahbauer EA, Han L, et al. The role of intervening hospital admissions on trajectories of disability in the last year of life: prospective cohort study of older people. BMJ 2015;350:h2361.

5 Teno JM, Gozalo P, Trivedi AN, et al. Site of death, place of care, and health care transitions among US Medicare beneficiaries, 2000-2015. JAMA 2018;320:264-71.

6 Van den Block L, Onwuteaka-Philipsen B, Meeussen K, et al. Nationwide continuous monitoring of end-of-life care via representative networks of general practitioners in Europe. BMC Fam Pract 2013;14:73.
7 Pivodic L, Pardon K, Miccinesi G, et al. Hospitalisations at the end of life in four European countries: a population-based study via epidemiological surveillance networks. J Epidemiol Community Health 2016;70:430-6.

8 Ko W, Deliens L, Miccinesi G, et al. Care provided and care setting transitions in the last three months of life of cancer patients: a nationwide monitoring study in four European countries. BMC Cancer 2014;14:960.

9 Elmstedt S, Mogensen H, Hallmans D-E, et al. Cancer patients hospitalised in the last week of life risk insufficient care quality - a population-based study from the Swedish Register of Palliative Care. Acta Oncol 2019;58:432-8.

10 Wright AA, Keating NL, Ayanian JZ, et al. Family perspectives on aggressive cancer care near the end of life. JAMA 2016;315:284-92.

11 Hanratty B, Lowson E, Grande G. Transitions at the end of life for older adults - patient, carer and professional perspectives: a mixed-methods study. 2014. Southampton, UK: NIHR Journals Library, 2014.

12 Coleman EA. Falling through the cracks: challenges and opportunities for improving transitional care for persons with continuous complex care needs. J Am Geriatr Soc 2003;51:549-55.

13 Sepúlveda C, Marlin A, Yoshida T, et al. Palliative care: the world Health organization's global perspective. J Pain Symptom Manage 2002;24:91-6.

14 Gruneir A, Silver MJ, Rochon PA. Emergency department use by older adults: a literature review on trends, appropriateness, and consequences of unmet health care needs. Med Care Res Rev 2011;68:131-55.

15 Murray SA, Kendall M, Boyd K, et al. Illness trajectories and palliative care. BMJ 2005;330:1007-11.

16 Lynn J, Adamson DM. Living well at the end of life: adapting health care to serious chronic illness in old age. St Monica: CA RAND Corp, 2003.

17 Ludvigsson JF, Otterblad-Olausson P, Pettersson BU, et al. The Swedish personal identity number: possibilities and pitfalls in healthcare and medical research. Eur J Epidemiol 2009;24:659-67.

18 Lunney JR, Lynn J, Foley DJ, et al. Patterns of functional decline at the end of life. JAMA 2003;289:2387-92.

19 Gill TM, Gahbauer EA, Han L, et al. Trajectories of disability in the last year of life. N Engl J Med 2010;362:1173-80.

20 Morin L, Vetrano DL, Rizzuto D, et al. Choosing wisely? measuring the burden of medications in older adults near the end of life: nationwide, longitudinal cohort study. Am J Med 2017;130:927-36.

21 Chaudhry SI, Murphy TE, Gahbauer E, et al. Restricting symptoms in the last year of life: a prospective cohort study. JAMA Intern Med 2013;173:1534-40.

22 Lunney JR, Lynn J, Hogan C. Profiles of older Medicare decedents. J Am Geriatr Soc 2002;50:1108-12.

23 Stolz E, Gill TM, Mayerl H, et al. Trajectories of late-life disability vary by the condition leading to death. J Gerontol A Biol Sci Med Sci 2020. doi:10.1093/gerona/glaa234. [Epub ahead of print: 17 Sep 2020].

24 Ludvigsson JF, Andersson E, Ekbom A, et al. External review and validation of the Swedish national inpatient register. BMC Public Health 2011;11:450.

25 Platt RW, Hutcheon JA, Suissa S. Immortal time bias in epidemiology. Curr Epidemiol Rep 2019;6:23-7.

26 Calderón-Larrañaga A, Vetrano DL, Onder G, et al. Assessing and measuring chronic multimorbidity in the older population: a proposal for its Operationalization. J Gerontol A Biol Sci Med Sci 2017;72:1417-23.

27 Gilbert T, Neuburger J, Kraindler J, et al. Development and validation of a hospital frailty risk score focusing on older people in acute care settings using electronic Hospital records: an observational study. Lancet 2018;391:1775-82. 
28 Halldén K. The Swedish educational system and classifying education using the ISCED-97. The intern. Mannheim: University of Mannheim, 2008.

29 Morin L, Johnell K, Laroche M-L, et al. The epidemiology of polypharmacy in older adults: register-based prospective cohort study. Clin Epidemiol 2018;10:289-98.

30 Wilson P. The misuse of the Vuong test for non-nested models to test for zero-inflation. Econ Lett 2015;127:51-3 https:// econpapers.repec.org/RePEc:eee:ecolet:v:127:y:2015:i:c:p:5153

31 Morin L, Todd A, Barclay S, et al. Preventive drugs in the last year of life of older adults with cancer: is there room for deprescribing? Cancer 2019;125:2309-17.

32 SAS Institute. The SAS system for windows. release 9.4 2011.

33 R Core Team. R: a language and environment for statistical computing. R foundation for statistical computing, 2019.

34 Benchimol EI, Smeeth L, Guttmann A, et al. The reporting of studies conducted using observational Routinely-collected health data (record) statement. PLoS Med 2015;12:e1001885.

35 Dalrymple U, Makwana A, Pring A. Older people's hospital admissions in the last year of life. Public Health England, 2020. Available: https://www.gov.uk/government/publications/ older-peoples-hospital-admissions-in-the-last-year-of-life/olderpeoples-hospital-admissions-in-the-last-year-of-life

36 Martinsson L, Lundström S, Sundelöf J. Quality of endof-life care in patients with dementia compared to patients with cancer: a population-based register study. PLoS One 2018;13:e0201051.

37 Davies N, Maio L, van Riet Paap J, et al. Quality palliative care for cancer and dementia in five European countries: some common challenges. Aging Ment Health 2014;18:400-10.
38 Bamford C, Lee R, McLellan E, et al. What enables good end of life care for people with dementia? A multi-method qualitative study with key stakeholders. BMC Geriatr 2018;18:302.

39 Ackermann RJ. Nursing home practice. Strategies to manage most acute and chronic illnesses without hospitalization. Geriatrics 2001;56:37-40. 43-4 passim.

40 Westerlund C, Tishelman C, Benkel I, et al. Public awareness of palliative care in Sweden. Scand J Public Health 2018;46:478-87.

41 Boockvar K, Fishman E, Kyriacou CK, et al. Adverse events due to discontinuations in drug use and dose changes in patients transferred between acute and long-term care facilities. Arch Intern Med 2004;164:545-50.

42 Yoo JW, Nakagawa S, Kim S. Integrative palliative care, advance directives, and hospital outcomes of critically ill older adults. Am J Hosp Palliat Care 2012;29:655-62.

43 Rocker G, Downar J, Morrison RS. Palliative care for chronic illness: driving change. CMAJ 2016;188:E493-8.

44 Detering KM, Hancock AD, Reade MC, et al. The impact of advance care planning on end of life care in elderly patients: randomised controlled trial. BMJ 2010;340:c1345.

45 Murray SA, Kendall M, Mitchell G, et al. Palliative care from diagnosis to death. BMJ 2017;356:j878.

46 ElMokhallalati Y, Bradley SH, Chapman E, et al. Identification of patients with potential palliative care needs: a systematic review of screening tools in primary care. Palliat Med 2020;34:989-1005.

47 Bach PB, Schrag D, Begg CB. Resurrecting treatment histories of dead patients: a study design that should be laid to rest. JAMA 2004;292:2765-70. 